Informationabouttheauthor: Luibov Karpets - Doctor of Philosophy, Candidate of Philology, Associate Professor Kharkiv State Academy of Physical Culture (Kharkiv, Ukraine)

e-mail: lubo.karpets@gmail.com

Сведения об авторе: Любовь Карпец - доктор философии, кандидат филологии, доцент, Харьковская государственная академия физической культуры, (Харьков, Украина)

e-mail: lubo.karpets@gmail.com

Informationabouttheauthor: Helena Kucherenko - Candidate of Philology, Associate Professor, Kharkov National University of Civil Engineering and Architecture, (Kharkov, Ukraine).

email:kucherenkoef@gmail.com

Сведения об авторе: Елена Кучеренко - кандидат филологии, доцент, Харьковский национальный университет строительства и архитектуры, (Харьков, Украина)

email:kucherenkoef@gmail.com

DOI:

\title{
BILINGUAL EXPLANATORY-GRAMMATICAL DICTIONARY AS A MEANS OF TEACHING A FOREIGN LANGUAGE
}

\author{
Tatiana Nikitina \\ Doctor of Philology, Professor \\ Pskov State University \\ (Pskov, Russia) \\ e-mail: cambala2007@yandex.ru
}

\begin{abstract}
The purpose of the project presented in this article is to create a multifunctional dictionary, which will be useful in teaching various types of speech activity and aspects of foreign language. This is achieved through the use of methods of comparative, contextual and linguoculturological analysis in the course of work on the project. The result of the study is the concept of a new type of educational dictionary - bilingual explanatory-grammatical (Russian-Hungarian). The article reveals the differences of this dictionary from traditional lexicographical sources, shows its advantages as a means of teaching a foreign language. The material in the first section of the dictionary is grouped by parts of speech. The second section implements the functional-communicative principle of material arrangement. Thus, the bilingual dictionary, based on the proposed model, provides a comprehensive approach to teaching Russian grammar to foreigners, and can also be useful for Russian-speaking users learning a foreign language.
\end{abstract}

Keywords: educational dictionary, non-native language teaching, Russian language, Hungarian language, adjective

\section{ДВУЯЗЫЧНЫЙ ТОЛКОВО-ГРАММАТИЧЕСКИЙ СЛОВАРЬ КАК СРЕДСТВО ОБУЧЕНИЯ НЕРОДНОМУ ЯЗЫКУ}

\author{
Татьяна Геннадьевна Никитина \\ Доктор филологических наук, профессор \\ Псковский государственный университет \\ (Псков, Россия) \\ e-mail: cambala2007@yandex.ru
}

\begin{abstract}
Аннотация. Цель научно-методического проекта, представляемого в данной статье - создание многофункционального учебного пособия словарного типа, которое будет полезным при обучении различным видам речевой деятельности и аспектам иностранного языка. Это достигается за счет использования в ходе работы над проектом таких методов лингвистического исследования, как сопоставительный, контекстуальный и лингвокультурологический анализ. Результатом исследования стала концепция учебного словаря нового типа - двуязычного толково-грамматического (русско-венгерского). В статье раскрываются отличия данного словаря от традиционных лексикографических источников, его преимущества как средства обучения неродному языку. Материал в первого раздела словаря группируется по частям речи. Здесь системно представлены их морфологические свойства и синтаксическая валентность. Во втором разделе реализуется функциональнокоммуникативный принцип расположения материала: макростатьи объединяют средства выражения пространственных, временных, причинных и других логико-грамматических отношений, изучаемых в курсе русского языка как иностранного (базовый уровень). Таким образом, двуязычный словарь, построенный по предлагаемой модели, обеспечивает комплексный (системно-функциональный) подход в обучении русской грамматике иностранцев, а также может быть полезен русскоязычным пользователям, изучающим иностранный язык.
\end{abstract}


ВВЕДЕНИЕ. Лингвометодическое обеспечение процесса обучения неродному языку - проблема, основательно разработанная в теоретическом плане и получившая реализацию в многочисленных учебных пособиях и лексикографических разработках. Однако по-прежнему одной из задач лингвометодического плана, требующих скорейшего решения, является создание многофункционального учебного пособия словарного типа, полезного в плане обучения различным аспектам неродного языка и видам речевой деятельности. Этим обусловлена актуальность нашего исследования, целью которого является разработка концепции такого пособия - учебного толково-грамматического русско-венгерского словаря. В свою очередь цель данной статьи - представить нашу концепцию, показывая отличия проектируемого словаря от традиционных лексикографических источников, а также его преимущества как средства обучения неродному языку.

ОБЗОР ЛИТЕРАТУРЫ. Отечественной лексикографией накоплен значительный опыт двуязычной репрезентации языкового материала и типологизации переводных словарей. В середине прошлого века академик Л. В. Щерба указывал на принципиальную ошибку составителей переводных словарей, состоящую в предположении адекватности систем описываемых языков (Shcherba, 1974), и советовал изучающим иностранный язык переходить от двуязычных словарей к толковым словарям, разработанным на изучаемом языке, т.к. только они в то время (работа Л. В. Щербы впервые была опубликована в 1940 г.) могли сформировать у обучающегося адекватное представление о функционировании иноязычного слова. Перед лексикографами же ставилась задача разработки двуязычных словарей нового, как сказали бы сейчас, активного типа. Таким образом, для всякой пары языков, по мнению Л. В. Щербы, нужно создавать четыре словаря - два толковых иностранных словаря с объяснениями на родном языке пользователя и два переводных словаря функционального типа с родного языка на иностранный (Shcherba, 1974). В. Г. Гак, интерпретируя и развивая лексикографическую концепцию Л. В. Щербы, конкретизирует типы двуязычных словарей в зависимости от их адресата: так, иностранно-русский словарь для русских должен быть преимущественно пассивным, русскоиноязычный же - преимущественно активным, и наоборот (Gak, 1964). В свою очередь он выделяет три типа иностранно-русских словарей: полный словарь общего типа, обеспечивающий понимание читаемого текста, переводной словарь, позволяющий переводчикам отыскивать нужные эквиваленты, и учебный словарь, назначение которого - дать представление не только о значении слова, но и его функционировании (Gak 1964). Анализируя опубликованные на тот момент учебные двуязычные словари, В. Г. Гак отмечает неоправданное объединение в них элементов общепереводного, переводческого, учебно-толкового словарей и делает вывод о том, что эти лексикографические источники - «суть словари смешанного типа, без четко дифференцированного назначения» (Gak 1964). В конце XX- начале XXI в. ситуация в двуязычной лексикографии кардинально изменилась. Уточнена и детализирована типология двуязычных словарей с учетом их функций (Dubichinskij 1998; Berkov 2004; Trifonov 2016). В русле лексикографических традиций совершенствуется концепция универсального словаря (Bulygina and Tripol'skaya 2016), разрабатываются и реализуются модели описания лексики в двуязычных словарях активного типа (Gak 1991; Latypova et. al., 2016), в том числе терминологических (Balkanov 2016). Лексикографы подчеркивают, что активный словарь, построенный на принципах антропоцентризма и функционализма, должен предлагать читателю такой объем информации, который демонстрирует правила использования языковой единицы и ее сочетаемостные возможности (Latypova et. al., 2016). Таким образом, активные словари специализируются на обеспечении процесса порождения речи, пассивные же - на обеспечении процесса понимания. Словари третьего типа - активно-пассивные, направлены как на рецепцию, так и на репродукцию (Dubichinskij 1998; Trifonov 2016).

Не вызывает сомнения тезис о том, что параметр активности является неотъемлемым для учебного двуязычного словаря (Trifonov 2016). В свою очередь учет принципов взаимосвязанного обучения аспектам языка и видам речевой деятельности позволяет признать оптимальным для использования в процессе обучения неродному языку словарь смешанного активно-пассивного типа. При этом ступень информативности и учебнометодической ценности словаря повысится, если составителю удастся усилить компонент системности в подаче грамматического материала. Эту задачу мы решаем в ходе разработки и реализации концепции учебного толково-грамматического русско-венгерского словаря.

МЕТОДЫ ИССЛЕДОВАНИЯ. Методом контекстуального анализа и анализа словарных дефиниций (в качестве источников материала использованы современные толковые словари (Kuznecov 2000; $\underline{\text { A magyar nyelv }}$ nagyszótára, 2006-2018; Magyar-oroszszótár, 2000-2019) нами были выявлены семантические и прагматические особенности лексических единиц, подлежащих описанию в толково-грамматическом русско-венгерском словаре (далее - ТГРВС). Методом сопоставительного анализа были установлены сходства и различия в семантической структуре, сочетаемостном потенциале и морфологических характеристиках соотносительных лексических единиц двух языков, которые затем были учтены при составлении словарных статей. Метод лингвокультурологического анализа позволил выявить специфику этнокультурного фона репрезентируемых в словаре русских лексических единиц, проявляющуюся в том числе в устойчивых сочетаниях, что также будет представлено в словаре на фоне венгерского языка с использованием соответствующих комментариев.

РЕЗУЛЬТАТЫ И ДИСКУССИЯ . Репрезентация частей речи в Толково-грамматическом русско-венгерском словаре, согласно нашей концепции, первая часть ТГРВС объединит в нескольких разделах лексические единицы по их принадлежности к частям речи. Именно так могут быть системно представлены грамматические 
категории русского языка на фоне родного языка пользователей: при совпадении грамматических значений будет показана специфика средств их выражения. В случае лакунарности отсылка (под знаком \#) к грамматическому справочнику, размещенному в заключительном разделе словаря, позволит получить или скорректировать представление об отсутствующем в родном языке грамматическом явлении, а материал словарной статьи представит его конкретными языковыми реализациями.

Объем словника, а значит и отбор материала для учебного словаря, адресованного иностранцам, изучающим русский язык, определяется лексическим минимумом соответствующего этапа обучения. В нашем случае это уровень А2 - базовый.

Представим нашу концепцию материалом словарных статей раздела «Имя прилагательное» - части речи, трудности освоения которой венграми обусловлены отсутствием в их родном языке категории рода (в словарной статье будут показаны примеры согласования русских прилагательных с существительными разной родовой принадлежности). Словосочетания со структурой имя прилагательное + имя существительное проиллюстрируют и согласование прилагательных с существительными в падеже (в венгерском языке падежные показатели в данном случае присоединяются только к существительным, что характерно также и для показателей множественного числа. Примеры таких словосочетаний даются следом за толкованием и венгерским эквивалентом (эквивалентами) заголовочного слова или при каждом из значений. Здесь венгерский пользователь, как и носитель русского языка, изучающий венгерский, получит представление не только об определенных морфологических свойствах имен прилагательных изучаемого языка, но и об особенностях их лексической сочетаемости. Следующая параметрическая зона словарной статьи представит читателю морфемную и словообразовательную структуру русского прилагательного. Этот структурный параметр важен для освоения формообразования прилагательных, прежде всего, форм сравнительной и превосходной степени, присутствующих в венгерском языке, но не имеющих такой вариативности, как в русском языке (аналитические и синтетические формы). Завершают словарную статью устойчивые словосочетания, в состав которых входит описываемое прилагательное. Здесь наблюдается как лексико-синтаксический параллелизм, так разного рода несовпадения - различия образной структуры и лексического состава. В ряде случаев материал этой параметрической зоны требует лингвокультурологического комментария.

В целом словарная статья выглядит следующим образом:

ВЫСО́КИй, -ая, -ое. 1. Значительный по протяженности снизу доверху, по высоте. -MAGAS. Bысокий дом - таgas ház; высокая башня - magas torony; высокое дерево - magas fa; Bысокие девушки - magas lányok; 6 высоких домах - magas házakban.

2. Значительный по количеству, уровню, ценности. - MAGAS, NAGY, KIVÁLÓ. Высокая награда - nagy (magas) jutalom; высокий результат - kiváló eredmény; высокое давление - таgas vérnуота́s; высокие иень magas árak; о высоких ценнах - magas árakról.

- Высок-ий.

- Ви́ше [кого, чего; чем кто, чем что], бо́лее (ме́нее) высо́кий [чем кто, чем что] - magasabb, nagyobb, kiválóbbv-minél, v-kinél.

- Са́мый (-ая, -ое) высо́кий (-ая, -ое), высший (-ая, -еe), высоча́йший (-ая,-еe) -legmagasabb, legnagyobb.

- (\#) Высо́к, высока́, высо́ко́, высо́ки́: Наши показатели не высоки - a teljesítményünk nem magas.

* Высокий старт - állórajt. * Высокого роста - magastermetü.

Несоответствий такого типа будет особенно много в сфере относительных прилагательных. Довольно часто логико-грамматические отношения, выражаемые в русском языке именными словосочетаниями с такими прилагательными, передаются в финно-угорских языках изафетными конструкциями и сложными словами с определительной первой частью. Поэтому словарные статьи, посвященные относительным прилагательным, содержат еще большее количество примеров межуровневых соответствий, в то время как зона формообразования остается не заполненной в силу отсутствия у относительных прилагательных способности образовывать формы степеней сравнения и краткие формы:

ДЕ́ТСКИЙ, -ая, -ое. Относящийся к детям, свойственный детям, предназначенный для детей. GYERMEKI; GYERMEK-. Детская любовь - gyermeki szeretet; детские забавы - gyermeki szórakozások; детский спектакль - gyermekelöadás; детский возраст - gyermekkor; детская песенка - gyermekdal; детская обувь-gyermekcipö; детская больнииа - gyermekkórház; о детских игpax-gyermekjátékokról.

- Дет-СК-ий (<дет-и).

$\bullet-$

- -

- -

* Детский сад - óvoda. * Детские ясли - bölcsőde.

Репрезентация функционально-семантических категорий в толково-грамматическом руссковенгерском словаре

Концепция лексикографической репрезентации функционально-семантических категорий была разработана нами на примере категории субъективной модальности (Nikitina, 2013). Под функциональносемантическими категориями (далее - ФСК) мы традиционно понимаем инвариантные логико-грамматические значения в совокупности с разноуровневыми языковыми средствами их выражения. В словаре ФСК мы предложили воплотить идею идеографического грамматического словаря, высказанную В.А. Белошапковой и 
И.Г. Милославским (Beloshapkova and Miloslavskij 1988). Иерархическая организация материала в словаре ФСК должна отражать структуру соответствующего функционально-семантического поля.

В учебном толково-грамматическом двуязычном словаре описанию ФСК посвящен отдельный раздел, наполнение и структурирование макростатей которого (Пространство, Время, Цель, Причина, Условие, Обладание, Адресат, Инструмент и др.), как и в первом, системно-грамматическом разделе словаря, определяется грамматическим минимумом для определенного уровня владения языком. В заголовок статьи выносится грамматическое средство выражения соответствующего значения с указанием синтаксической конструкции его реализации и венгерским функциональным эквивалентом (эквивалентами). Комментарии указывают на сферу употребления, примеры использования демонстрируют межъязыковые соответствия. В макростатьях, предполагающих структурирование в соответствии с изученным функциональнограмматическим материалом, выделяются подрубрики (напр.: УСЛОВИЕ: РЕАЛЬНОЕ УСЛОВИЕ; ИРРЕАЛЬНОЕ УСЛОВИЕ). ОстаЛЬные рубрики идеографически не структурируются. Материал внутри рубрик и подрубрик располагается в алфавитном порядке:

\section{ПРИЧИНА}

В СИЛУ (+ Р.п. чего), в офиц. речи. Vmi KÖVETKEZTÉBEN, vmi FOLYTÁN. В силу сложившихся обстоятельств - а körülmények folytán; в силу привычки - puszta szokásból.

И3 (+ Р.п.чего). -BÓL, -BÖL. Из ревности - féltékenységböl; из любопытства - kiváncsiságból; из благодарности - hálából.

И3-3А (+ Р.п. чего, кого). MIATT, -BÓL, -BÖL, -TÓL, -TÖL. Из-за меня-miattam; из-за этого - emiatt; из-за пустяка - valami semmiség miatt; из-за женщины - а пӧ тіаtt; из-за шума ничего не сльшно - а zаjtól semmit se lehet hallani; из-за чего? - miért?

OT (+ Р.п. чего). -BÓL, -BÖL, -TÓL, -TÖL, -BA, -BE. Om горя - bánatában; om paдоcmu - az örömtöl (öröméböl); дрожать om cmpaxa - remegni a félelemtöl; cmpadamь om жары-szenvedni a höségtöl; yмepemь om paнbl-sebébe belehal.

ОТ ТОГО [...], ЧТО, в сложном предложении. (AZÉRT) ... MERT. Я не приехал от того, что не мог nem jöttem el, mert nem tudtam.

ПОТОМУ [...,]ЧТО, в сложном предложении. (AZÉRT) ... MERT; MIVEL. Я устал, потому что ночью не сnал.-Fáradtvagyok, miveléjjelnemaludtam.

ТАК КАК, в сложном предложении. (AZÉRT) ... MERT; MIVEL. Он не может передать ей книгу, так как она уже уехала. - Nem tudja átadni neki a könyvet, mivel ö már elutazott.

ЗАКЛЮЧЕНИЕ - Таким образом, учебный словарь нового типа - двуязычный толково-грамматический, сочетающий системно-грамматический и функционально-коммуникативный принципы подачи материала, будет полезен при использовании в обучении неродному языку как сознательного (когнитивного), так и коммуникативно-деятельностного подходов. Модель комплексной репрезентации материала позволяет знакомить пользователя этого словарного пособия с материалом лексического и грамматического уровней, решать задачи обучения как рецептивным, так и продуктивным видам речевой деятельности. Несмотря на то, что русский язык является здесь исходным, словарь не будет для венгерского читателя пособием исключительно пассивного типа. Обнаружив здесь перевод неизвестного русского слова, он получит информацию не только о его значении, но и о грамматических особенностях в полном их объеме, о возможностях речевой реализации слова. Системная репрезентация грамматики в направлении от родного языка к изучаемому не обеспечила бы полного представления о грамматическом уровне последнего в силу типологических различий. Описание в толково-грамматическом словаре материала функциональносемантических категорий повышает его ценность как пособия активного типа. Отсюда следует, что толковограмматический словарь, построенный по предлагаемой модели, можно охарактеризовать как активный для носителя исходного языка и пассивно-активный для читателя, изучающего данный язык. В целом же при таком подходе достаточно будет не четырех, а двух словарей, представляющих материал пары контактирующих в учебном процессе языков.

\section{LIST OF REFERENCES}

A Magyar nyelv nagyszótára (2006-2018). Budapest: MTA Nyelvtudományi Intézet. V. 1-8.

Balkanov, I. V. (2016). Megastruktura otraslevogo slovarya (na material voennyh dvuyazychnyh slovarey XX veka) [Megastructure of the industry dictionary (on the material of military bilingual dictionaries of the twentieth century)]. Vestnik Moskovskogo universiteta, ser. 22 (3), 101-113.

Beloshapkova, V. A. \& Miloslavskiy, I. G. (1988). Voprosy ideograficheskoy grammatiki russkogo yazyka [Questions of ideographic grammar of the Russian language]. Ideograficheskie aspekty grammatiki. Moskva: MGU, 3-11.

Berkov, V. P. (2004). Dvuyazychnaya leksikografiya [Bilingual lexicography]. Moskva: AST.

Bulygina, E. Yu. \& Tripol'skaya, T. A. (2016). Universal'nyiy i aktivnyiy slovar': razvitie leksikograficheskoy traditsii ili vozvrashchenie $k$ istokam [Universal and active vocabulary: development of the lexicographic tradition or a return to basics]. Vestnik Novosibirskogo gosudarstvennogo pedagogicheskogo universiteta (2), 7-23.

Gak, V. G. (ed.) (1991). Francuzsko-russkiy slovar' [French-Russian dictionary]. Moskva: Rus. yaz.

Gak, V. G. (1964). O raznyh tipah dvuyazychnyh slovarey [About different types of bilingual dictionaries].Tetradi perevodchika (2), 71-78. 
Dubichinskiy, V.V. (1998). Teoreticheskaya i prakticheskaya leksikografiya: uchebnoe posobie. Vena - Har'kov: Wiener Slawistischer Almanach; Har'kovskoe leksikograficheskoe obshchestvo.

Kuznecov, S. A. (ed.) (2000). Bol'shoy tolkovyiy slovar' russkogo yazyka [Large explanatory dictionary of the Russian language]. Saint-Petersburg: Norint.

Latypova, L. A., Sirazeeva, A. F. \& Sharifullina, Zh. A. (2016). Mikrostruktura dvuyazychnogo slovarya aktivnogo tipa [Microstructure of bilingual active dictionary]. Filologia i kul'tura (2), 93-98.

Magyar-orosz szótár (2000-2019). https://hungarian_russian.academic.ru/ [16.02.2019].

Trifonov, A. S. (2016). Osnovnyie parametry tipologizacii uchebnyh slovarey [The main parameters of typology of training dictionaries]. Teoreticheskaya i prikladnaya lingvistika (2), 80-90.

Shcherba, L. V. (1974). Opyt obshchey teorii leksikografii [The experience of the General theory of lexicography].Yazykovaya sistema i rechevaya deyatel'nost'. Leningrad: Nauka, 265-303.

\section{For citation:}

Nikitina, T.G. (2019) BILINGUAL EXPLANATORY-GRAMMATICAL DICTIONARY AS A MEANS OF TEACHING A FOREIGN LANGUAGE. International Scientific-Pedagogical Organization of Philologists “ WEST-EAST" (ISPOP). Scientific Journal WEST-EAST. Vol 1/1 N1 (October, 2019). pp. 156-160. doi:

\section{Для цитирования:}

Никитина, Т. Г. (2019) ДВУЯЗЫЧНЫЙ ТОЛКОВО-ГРАММАТИЧЕСКИЙ СЛОВАРЬ КАК СРЕДСТВО ОБУЧЕНИЯ НЕРОДНОМУ ЯЗЫКУ // International Scientific-Pedagogical Organization of Philologists “WEST-EAST” (ISPOP). Scientific Journal WEST-EAST. Vol 1/1 N1 (October, 2019). C. 156-160. doi:

Information about the author: Nikitina Tatiana Gennadievna - DrHab (philology), Professor, Pskov State University (Pskov, Russia)

e-mail: cambala2007@yandex.ru

Сведения об авторе: Никитина Татьяна Геннадьевна - доктор филологических наук, Псковский государственный университет (Псков, Россия)

e-mail: cambala2007@yandex.ru 